\title{
HIGH TEMPERATURE EFFECTS ON THE NANOINDENTATION BEHAVIOUR OF POLYETHYLENE-BASED NANOCOMPOSITES
}

\author{
A.S. ALGHAMDI ${ }^{1}$, I.A. ASHCROFT ${ }^{2}$ \& M.O. $\mathrm{SONG}^{3}$ \\ ${ }^{1}$ Mechanical Engineering Department, Hail University, Saudi Arabia. \\ ${ }^{2}$ Mechanical, Materials and Manufacturing Engineering, University of Nottingham, UK. \\ ${ }^{3}$ Department of Materials, Loughborough University, UK.
}

\begin{abstract}
This paper illustrates the dependence of the near-surface properties of polyethylene-based nanocomposites on the temperature and the nanofiller content using nanoindentation techniques. The specimens were manufactured by melt processing a premixed blend of 75 wt. \% ultra-high molecular weight polyethylene (UHMWPE) and 25 wt.\% high-density polyethylene (HDPE) with 0.5, 1 and 3 wt.\% multiwalled carbon nanotube (MWCNT) or $0.5,1$ and 2 wt.\% inorganic clay. The results showed that the incorporation of MWCNT can increase the indentation resistance, with indentation resistance increasing with filler content. The indentation resistance was significantly increased with the addition of $1 \mathrm{wt} . \%$ clay nanoparticles. However, increasing the volume fraction of clay nanoparticle further resulted in a reduction in the indentation resistance. The indentation hardness and elastic modulus were significantly increased with the incorporation of both MWCNT and clay nanoparticles at room temperature. At elevated temperatures, up to $65^{\circ} \mathrm{C}$, a significant reduction was observed in the indentation resistance, hardness and elastic modulus, which indicated a thermal softening of the materials. However, it is interesting to find that the presence of the nanoparticle can enhance these properties at both room and high temperatures. Therefore, it is important to consider these variations in the near-surface properties of polyethylene-based nanocomposites when using such materials at various ambient temperatures.

Keywords: Nanoindentation, polyethylene, nanocomposite, nanotubes, nanoclay.
\end{abstract}

\section{INTRODUCTION}

Depth sensing indentation (DSI), or nanoindentation, is an advanced mechanical testing technique that is capable of providing valuable information about the near-surface properties of solid polymers, such as the indentation elastic modulus, indentation hardness and elastic-plastic, viscoelastic and viscoplastic behaviour [1]. This technique has become increasingly popular in the investigation of the near-surface properties of polymer nanocomposites and their correlation to the nanoparticle loading [2-7]. However, the nanoindentation technique to date has been limited to investigating the near-surface properties of polymers at room temperature, whereas the properties of many engineering polymers are significantly affected by temperature within their service range. For example, UHMWPE is often used in impact protection applications where the high strain rates involved can induce significant increases in temperature and subsequent thermal softening [8]. Recent developments in nanoindentation instruments have increased the capability to perform nanomechanical testing at elevated temperatures. Therefore, for better understanding of the near-surface properties of polymers in various environments and temperatures ranges and to meet environmental and commercial concerns, some researchers have used the nanoindentation technique at high temperature to perform a reliable measurement of the temperature-dependent properties [9-11]. It is important to investigate the temperature-dependent properties of certain materials at their in-service temperature to avoid unexpected behaviour or failure. To date, no work has been carried out to investigate the near-surface properties of polyethylene-based nanocomposites at elevated 
temperatures by means of DSI. The materials investigated in this work were desired to replace the UHMWPE in helmets and body armour protection with improved processability and low cost. The dependence of the near-surface properties of polyethylene-based nanocomposites on temperature was investigated. These properties include the indentation hardness, elastic modulus and creep resistance. The correlation between the near-surface properties of polyethylene-based nanocomposites and nanoparticle loading at various temperatures was also evaluated. The range of temperature was selected according to the expected service climate and below the recrystallisation temperature of such materials.

\section{EXPERIMENTAL METHODS}

\subsection{Materials}

The materials tested in this study were Ultra-high Molecular Weight Polyethylene/High-Density Polyethylene (UHMWPE/HDPE) blended polymers with multiwalled carbon nanotube (MWCNT) or inorganic nanoclay fillers. Nascent UHMWPE powders (Sabic ${ }^{\circledR}$ UHMWPE 3548) were purchased from (Saudi Basic Industries Corporation [SABIC], Jubail, Saudi Arabia 2010), which had an average molecular weight of $3 \times 10^{6} \mathrm{~mol} / \mathrm{g}$. HDPE powders (ExxonMobil $^{\mathrm{TM}}$ HDPE HMA014) were purchased from ICO Ltd (ExxonMobil Chemical Belgium, Europe 2010). Natural Hectorite nanoclay (BENTONE ${ }^{\circledR}$ HC Hectorite Clay) was supplied by Elementis Specialties Inc. in powder form, with an average particle size of less than $75 \mu \mathrm{m}$ and an average density of $2600 \mathrm{~kg} / \mathrm{m}^{3}$ (Elementis Specialties, East Windsor, USA 2010). Hectorite is a type of mineral clay that belongs to the Smectite group, formed from high silica content volcanic ash. The method by which the Hectorite Nanoclay is dispersed within the Polyethylene matrix is protected by patent WO/2010/106358. Multiwalled Nanotubes (NANOCYL ${ }^{\mathrm{TM}} \mathrm{NC7000)}$ with an average outside diameter of $9.5 \mathrm{~nm}$ and an average length of $1.5 \mu \mathrm{m}$, were provided by Nanocyl (Nanocyl, Sambreville, Belgium 2009). Butylated hydroxytoluene and Tris (nonylphenyl) phosphate, supplied by Sigma-Aldrich (Sigma-Aldrich Company Ltd, Dorset, England 2010), were used as primary and secondary antioxidants, to maintain the long term thermal stability and melt processing stability, respectively.

\subsection{Processing}

An in-house pre-mix technology was used to incorporate the nanofillers into the UHMWPE and HDPE powders. A twin-screw extruder from Randol Technology Ltd. (Staffordshire, UK) was then used to blend the UHMWPE and HDPE powders pre-mixed with MWCNT or nanoclay to form nano-filled UHMWPE/HDPE blends with various nanoparticle contents, as shown in Table 1. A blend of $75 \mathrm{wt}$.\% UHMWPE and $25 \mathrm{wt} \% \%$ HDPE, abbreviated to U75H25, was used as the hybrid PE matrix to accommodate the nanofillers. During processing, the mixing temperature was controlled using five zones from feeding port to die, the processing parameters are shown in Table 2. Compression moulding was used to mould the nanocomposite materials. The raw material was placed into a square mould $(100 \times 100 \times 1.65 \mathrm{~mm})$, and then heated to $190^{\circ} \mathrm{C}$, which is higher than the melting point of the composite (approximately $135^{\circ} \mathrm{C}$ ). Various mould pressures (154, 232, 309, and $386 \mathrm{MPa}$ ) were investigated to optimise the properties of the material such as hardness and crystallinity. Various holding times at maximum pressure $(10,15$ and $30 \mathrm{~min})$ were also used to identify the most appropriate moulding parameters. The optimal moulding pressure and holding time were $309 \mathrm{MPa}$ and $15 \mathrm{~min}$, respectively, which resulted in the highest values of hardness and 
Table 1: Nanofiller content.

\begin{tabular}{lcc}
\hline Base material & Filler & Filler content wt.\% \\
\hline $\mathrm{U} 75 \mathrm{H} 25$ & MWCNT & $0,0.5,1,3$ \\
$\mathrm{U} 75 \mathrm{H} 25$ & Clay & $0,0.5,1,2$ \\
\hline
\end{tabular}

Table 2: Processing method parameters.

\begin{tabular}{lcccccc}
\hline & \multicolumn{6}{c}{ Processing temperature $\left({ }^{\circ} \mathrm{C}\right)$} \\
\cline { 2 - 7 } Extruder speed $(\mathrm{rpm})$ & Zone 1 & Zone 2 & Zone 3 & Zone 4 & Die & Cooling \\
\hline 190 & 220 & 250 & 260 & 270 & 280 & water \\
\hline
\end{tabular}

crystallinity. After compression moulding, the mould was cooled to room temperature using water. Specimens of dimensions $10 \times 10 \times 1.65 \mathrm{~mm}$ were then cut from the plaques.

\subsection{Material testing and characterisation}

Depth sensing indentation (DSI) experiments were performed on the specimens at controlled machine chamber temperatures of $25^{\circ} \mathrm{C}, 45^{\circ} \mathrm{C}$ and $65^{\circ} \mathrm{C}$, using a NanoTest 600 from Micro Materials Ltd (Wrexham, UK). A Berkovich indenter, with face angle of $65.3^{\circ}$, was used to make at least 10 indents with $40 \mathrm{mN}$ maximum load, $600 \mathrm{~s}$ dwell period and $2 \mathrm{mN} / \mathrm{s}$ loading and unloading rates. The results were analysed using the Oliver and Pharr method [12], and the average curves were plotted using Excel. In this method, the initial portion of the unloading curve is described by the power low relation:

$$
P=\alpha\left(h-h_{\mathrm{r}}\right)^{m}
$$

where $P$ is the load, $\alpha$ and $m$ are constants determined by curve fitting, $h$ is penetration depth and $h_{\mathrm{r}}$ is the depth of the residual impression. The contact stiffness $(S)$ can be obtained by:

$$
S=\frac{d P}{d h}\left(h=h_{\max }\right)=m \alpha\left(h_{\max }-h_{\mathrm{r}}\right)^{m-1}
$$

The contact depth $\left(h_{\mathrm{c}}\right)$ at maximum load $\left(P_{\max }\right)$ can be estimated using:

$$
h_{\mathrm{c}}=h_{\max }-\varepsilon \frac{P_{\max }}{S}
$$

where $\varepsilon$ is a constant related to the geometry of indenter, which is 0.75 for the Berkovich indenter, $h_{\max }$ is the maximum penetration depth. Thus, the projected contact area $\left(A_{\mathrm{c}}\right)$ is determined from $\left(h_{\mathrm{c}}\right)$ by the following relation:

$$
A_{\mathrm{c}} \approx 24.5 h_{\mathrm{c}}^{2}
$$

and hence the indentation hardness $(H)$ is:

$$
H=\frac{P_{\max }}{A_{\mathrm{c}}}=\frac{P_{\max }}{24.5 h_{\mathrm{c}}^{2}}
$$


The reduced modulus can be calculated from stiffness $(S)$ using the relation:

$$
S=\frac{d P}{d h}=\beta \frac{2}{\sqrt{\pi}} E_{\mathrm{r}} \sqrt{A}
$$

where, $A=24.5 h_{\mathrm{p}}{ }^{2}, E_{\mathrm{r}}$ is the reduced modulus and $\beta$ is a correction factor, which depends on the type of indenter (1.034 for Berkovich indenter). Consequently, the elastic modulus $\left(E_{\mathrm{s}}\right)$ for the specimen can be calculated using the equation:

$$
\frac{1}{E_{r}}=\frac{\left(1-v_{\mathrm{s}}\right)^{2}}{E_{\mathrm{s}}}+\frac{\left(1-v_{\mathrm{i}}\right)^{2}}{E_{\mathrm{i}}}
$$

where, $E_{\mathrm{s}}, v_{\mathrm{s}}$ and $E_{\mathrm{i}}, v_{\mathrm{i}}$ are the elastic moduli and the Poisson's ratios of the specimen and the indenter, respectively, $\left(E_{\mathrm{i}}=1141 \mathrm{GPa}, v_{\mathrm{i}}=0.07\right)$.

For the materials used in this study, a bulge or (nose) effect was found during the initial portion of unloading as a result of creep, which can lead to errors in the calculation of contact depth and contact stiffness. Therefore, a dwell time of $600 \mathrm{~s}$ was introduced at maximum load to minimise this effect of viscoelastic behaviour. In this study, the Oliver and Pharr method was used to compare the mechanical resistance of the blends and nanocomposites under identical testing conditions.

To characterise the nanofiller dispersion and the microstructure of the U75H25 nanocomposites, several experimental techniques were used. These included Differential Scanning Calorimetry (DSC), X-ray Diffraction (XRD), Scanning Electron Microscopy (SEM), Transmission Electron Microscopy (TEM) and Thermogravimetric Analysis (TGA). The details of these techniques are discussed in this section.

Differential Scanning Calorimetry (DSC), (TA instruments, Shimadzu DSC60) was used to analyse the effect of different compression moulding parameters and nanofiller content on the crystallinity of the blend and nanocomposites. The specimens, with average mass of $5 \pm 0.2 \mathrm{mg}$, were sealed in aluminium pans and heated from $20^{\circ} \mathrm{C}$ to $180^{\circ} \mathrm{C}$ at a rate of $10^{\circ} \mathrm{C}$ per minute. The mass fraction degree of crystallinity was then determined by comparing the heat of fusion with that for fully crystalline polyethylene at the equilibrium melting point $(290 \mathrm{~kJ} / \mathrm{kg}$ ) [13]. X-ray Diffraction (XRD) was used to investigate dispersion of the clay particles using a Philips X'Pert X-ray diffractometer (anode $40 \mathrm{kV}$, filament current $35 \mathrm{~mA}$ ) with Nickel-filtered $\mathrm{Cu}-\mathrm{K} \alpha_{1}(\lambda=0.1542 \mathrm{~nm})$ radiation at a scan speed of $1 \%$ min from PANalytical company (Almelo, The Netherlands). The surface morphology was investigated using a Philips XL30 ESEM-FEG from FEI Company (Eindhoven, The Netherlands). The dispersion of CNT was studied after fracturing the samples in liquid nitrogen, then coating them using platinum. A JEOL 2000FX Transmission Electron Microscopy (TEM) from JEOL Ltd. (Welwyn Garden, UK) was used to analyse the dispersion of clay into the blend matrix. A PC controlled ultra-microtome with a diamond knife from RMC products, Boeckeler Instruments (Boeckeler Instruments, Inc., Butterfield Drive Tucson, Arizona, USA) was used for specimen cutting. The specimen and knife temperatures were set at $-120^{\circ} \mathrm{C}$ and $-100^{\circ} \mathrm{C}$, respectively. The final section thickness was $90 \mathrm{~nm}$ using $1 \mathrm{~mm} / \mathrm{s}$ cutting speed, which was then placed on a standard copper grid ring. The Thermogravimetric Analysis (TGA) from TA instruments, SDT Q600 (Crawley, UK) was used to analyse the thermal degradation behaviour of the polyethylene-based nanocomposites. The measurements were carried out in air at a heating rate of $40^{\circ} \mathrm{C} / \mathrm{min}$ and an air flow of $100 \mathrm{ml} / \mathrm{min}$ for cooling. The sample size was $16-17 \mathrm{mg}$, which was placed in a platinum pan and heated to $600^{\circ} \mathrm{C}$. 


\section{RESULTS AND DISCUSSION}

\subsection{Nanoparticle dispersion}

Nanoparticle dispersion is a very important factor in the manufacture of nanocomposites as it can affect the mechanical and rheological properties of the composite. SEM and TEM were used to analyse nanoparticle dispersion in the U75H25 matrix, as shown in Figs 1 and 2. It can be seen that there are homogenous dispersions of CNT at low volume fraction $(0.5$ and 1 wt.\%), with no large aggregates of nanoparticles (Fig. 1a and b). For higher volume fractions of CNT, large aggregations can be seen in Fig. 1c, which indicates that this volume fraction is greater than the percolation threshold of the dispersion of CNT into the U75H25 blend. Figure 2a shows an individual nanoclay layer in the blend matrix, which is the dark region on the image. XRD experiments were also carried out to investigate nanoclay dispersion with the results shown in Fig. 2b. It can be seen from the XRD profiles that the peak seen with the original clay is not seen with the U75H25/clay nanocomposites, which is a typical feature of exfoliation. This supports the identification of the single clay layer in the TEM investigation of the U75H25/clay nanocomposites.

\subsection{Thermal degradation}

The thermogravimetric analysis curves of $\mathrm{U} 75 \mathrm{H} 25$ and $\mathrm{U} 75 \mathrm{H} 25 /$ nanocomposites are shown in Fig. 3. The thermal degradation starts at approximately $275^{\circ} \mathrm{C}$ and then thermal stability breaks down in the range of $475-575^{\circ} \mathrm{C}$. It can be seen that the thermal stability of the
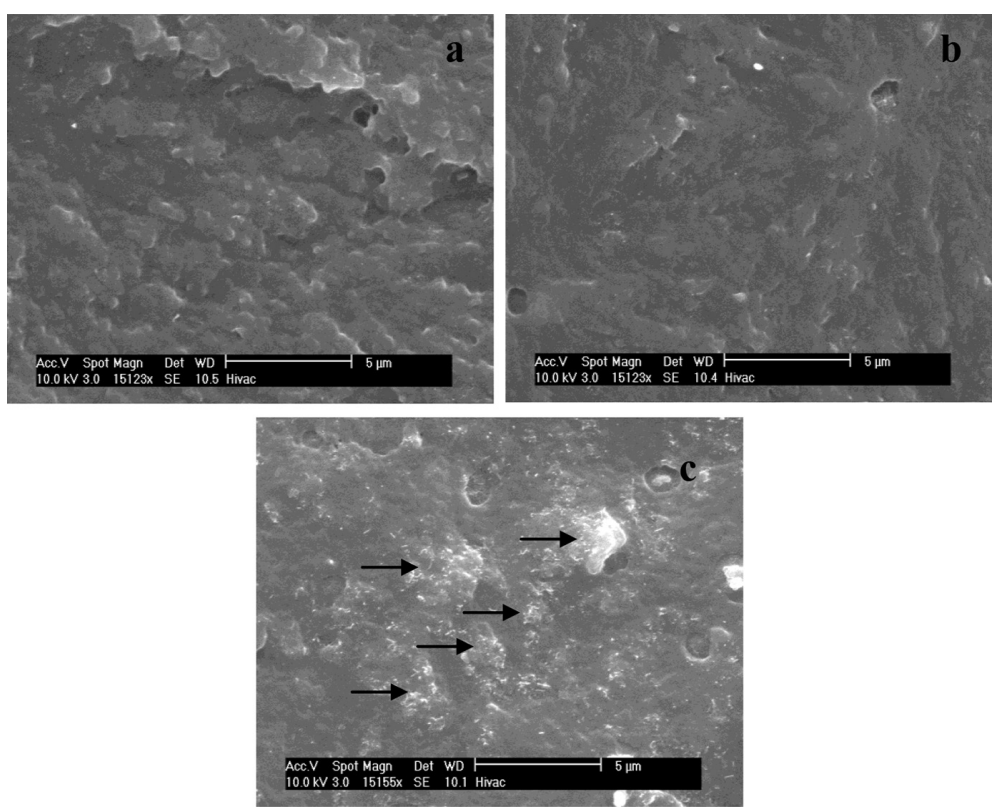

Figure 1: Scanning electron microscopy images for CNT dispersion in the U75H25 matrix: (a) 0.5 wt.\% carbon nanotube (CNT), (b) 1 wt.\% CNT and (c) 3 wt.\% CNT (arrows indicate the CNTs aggregations). 

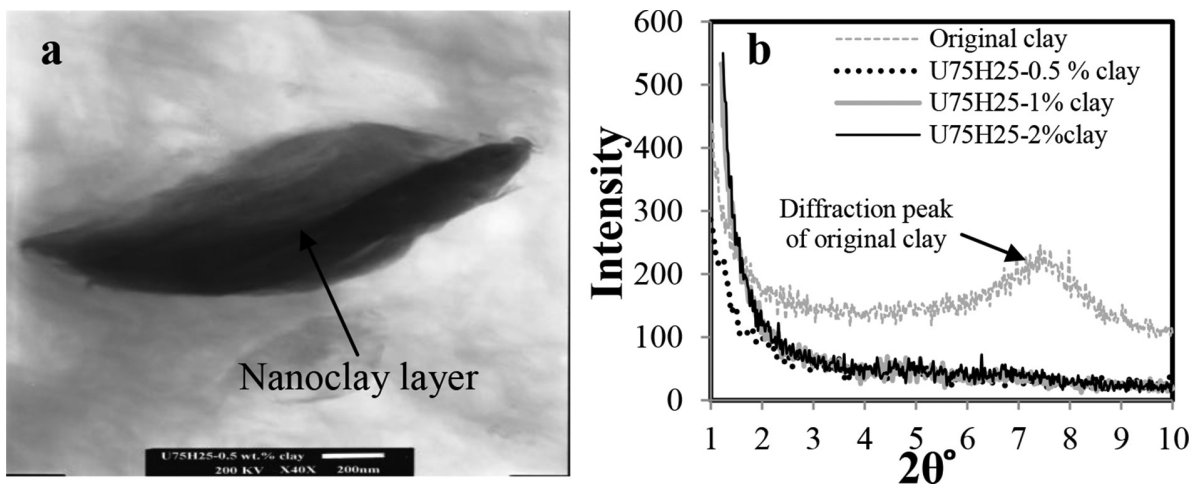

Figure 2: (a) Transmission electron microscopy image for the dispersion of clay into the blend matrix and (b) X-ray diffraction pattern.
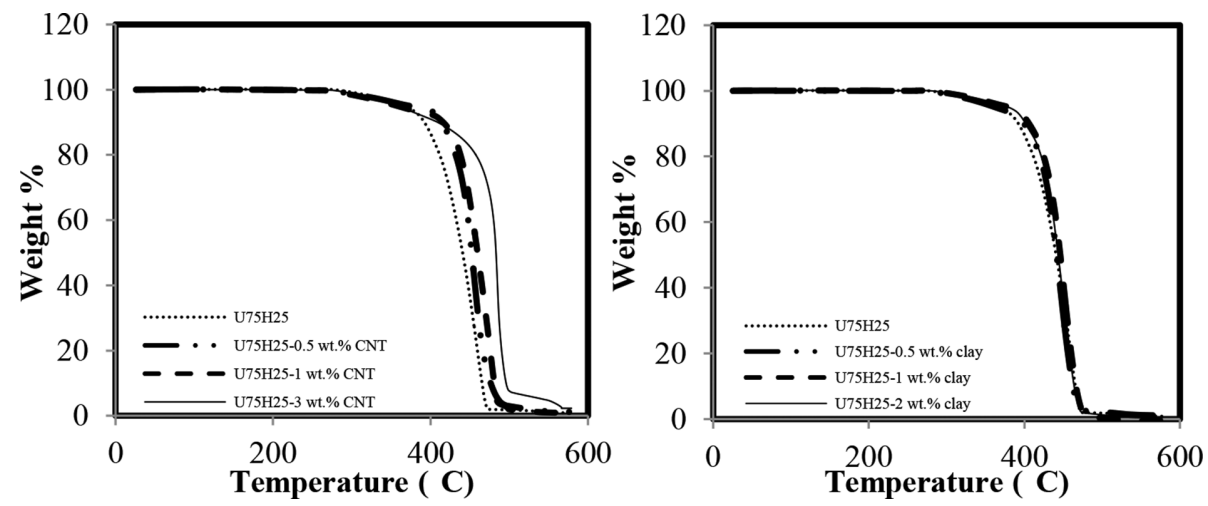

Figure 3: TGA results for the $\mathrm{U} 75 \mathrm{H} 25$ blend and the $\mathrm{U} 75 \mathrm{H} 25$-based nanocomposites.

$\mathrm{U} 75 \mathrm{H} 25-\mathrm{CNT}$ is higher than the $\mathrm{U} 75 \mathrm{H} 25$ blend and it appears to increase as the CNT volume fraction increases. For instance, the temperaturtfe at 20\% mass loss of the U75H25-3 wt.\% $\mathrm{CNT}$ is approximately $46^{\circ} \mathrm{C}$ higher than the $\mathrm{U} 75 \mathrm{H} 25$ blend. This can possibly be explained by the formation of a thermally stable cross-linked carbonised layer on the nanoparticle surface during the thermal degradation, which tends to hinder the diffusion. On the other hand, the addition of clay nanoparticles shows no effect on the thermal degradation of the blend, which indicates the significant effect of the nanoparticle type on the thermal properties of the polyethylene-based nanocomposites.

\subsection{Nanoindentation behaviour}

In this study, the effect of the degree of crystallinity is negligible for the blends and the nanocomposites, as no significant change was observed from the DSC tests (crystallinity values $\sim 54 \pm 1.2$ ). Figure 4 shows loading-holding-unloading curves of the U75H25 blend and its nanocomposites with various volume fractions. Generally, it can be observed that the incorporation of CNT or clay nanoparticles can result in a reduction in the penetration depth, which 

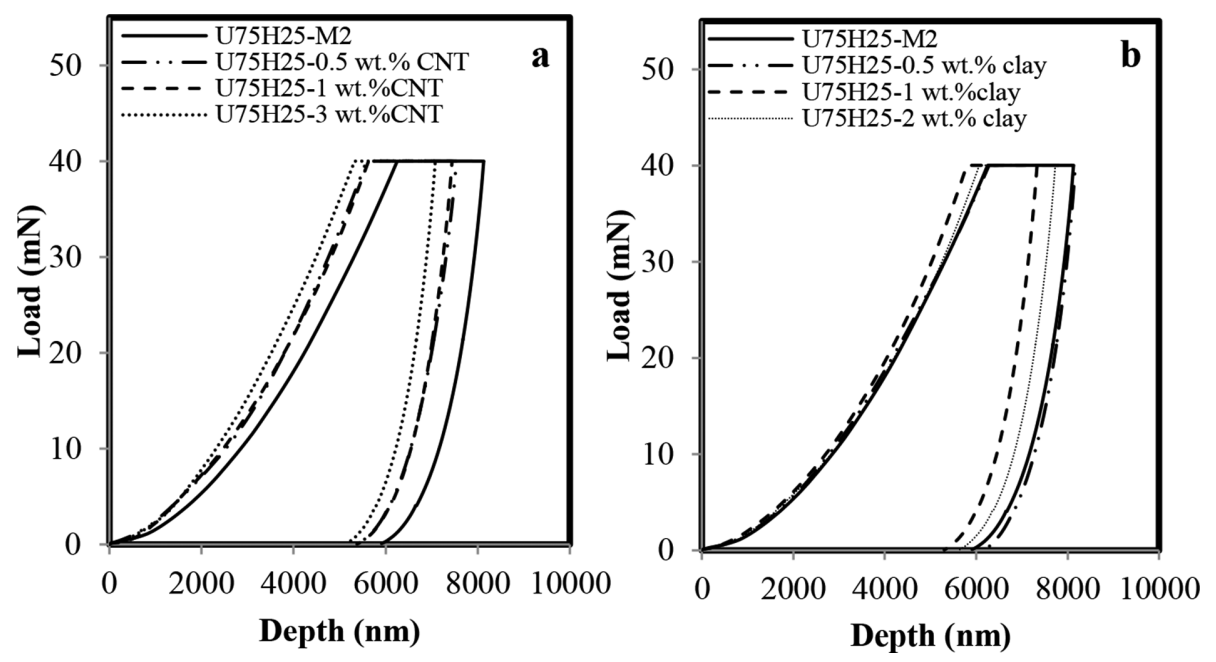

Figure 4: Nanoindentation behaviour of: (a) U75H25-carbon nanotube and (b) U75H25-clay.
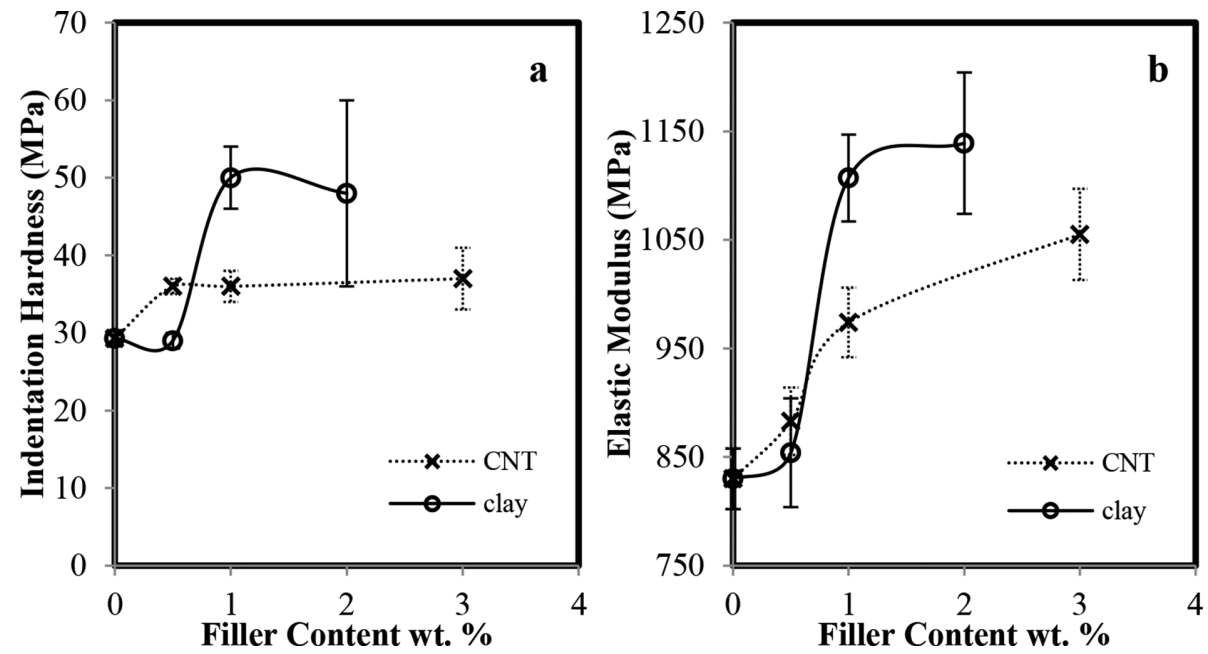

Figure 5: Dependence of the (a) indentation hardness and (b) elastic modulus on the nanoparticle loading.

indicates an increase in the hardness, stiffness and creep resistance of the nanocomposite. The addition of $2 \mathrm{wt} . \%$ clay nanoparticles displaces the curve to a higher penetration depth compared with $1 \mathrm{wt} \%$ clay. This can be attributed to the formation of intercalation of the clay platelets at high volume fraction and the poor distribution of clay nanoparticle in the $\mathrm{U} 75 \mathrm{H} 25$ matrix. The presence of nanofillers with high strength and surface area to volume ratios leads to an increase in the hardness. The addition of 1 and $2 \mathrm{wt} . \%$ clay results in a significant increase in the indentation hardness (42\%). However, increasing the CNT volume fraction (more than 0.5 wt.\%) shows no effect on the indentation hardness, as seen in Fig. 5a. The elastic modulus values were calculated using eqn (7) and the results are shown in Fig. 5b. It can be seen that the elastic modulus increases with increasing volume fraction of the nanofiller. This can be deduced 
from the change of the slope of the unloading curve. Modulus and stiffness (slope of the unloading curve) have a direct relationship as shown in eqn (6) and increasing the stiffness will lead to a higher modulus. It is interesting to see transition values for the elastic modulus at $0.5 \mathrm{wt} . \%$ of the nanofiller. This is obvious for the clay nanoparticle where a sharp increase in the modulus occurs. This can be attributed to the 2D geometry and larger size of the clay platelets. These results can be used as evidence that nanoparticle geometry can significantly affect the indentation behaviour of polyethylene-based nanocomposites.

\subsection{Temperature effects on the nanoindentation properties}

To investigate the effect of nanoparticle addition on the nanoindentation behaviour at various temperatures, a comparison of the effect of nanoparticles on the indentation penetration depth is shown in Fig. 6. The presence of the nanoparticles leads to a reduction in the penetration depth. The reduction in the penetration depth can be increased by increasing the volume fraction of the nanofiller. Increasing the temperature can lead to a significant increase in the indentation penetration depth. For example, at $65^{\circ} \mathrm{C}$ the indentation penetration depth of the U75H $25-1$ wt. \% CNT and U75H25-1 wt.\% clay increases by $18 \%$ and $21 \%$, respectively, compared with the indentation depths at room temperature.

The indentation hardness and elastic modulus were calculated following the same analysis procedure used in the room temperature experiments. Figure 7 shows the indentation hardness and elastic modulus of the polyethylene-based nanocomposites at various temperatures $\left(25^{\circ} \mathrm{C}, 45^{\circ} \mathrm{C}\right.$ and $\left.65^{\circ} \mathrm{C}\right)$. It can be seen that increasing the temperature from $25^{\circ} \mathrm{C}$ to $45^{\circ} \mathrm{C}$ can cause a significant reduction in the indentation hardness of the polyethylene-based nanocomposites in the range of 25-34\%. Further reduction in the indentation hardness can be observed at a higher temperature. However, only a small difference (up to 10\%) can be found between the indentation hardness values at $45^{\circ} \mathrm{C}$ and $65^{\circ} \mathrm{C}$. Testing the materials at high temperatures also induces a significant effect on the elastic modulus as seen in Fig. 7. Increasing temperature by $20^{\circ} \mathrm{C}$ can result in a significant reduction in the elastic modulus values between $30 \%$
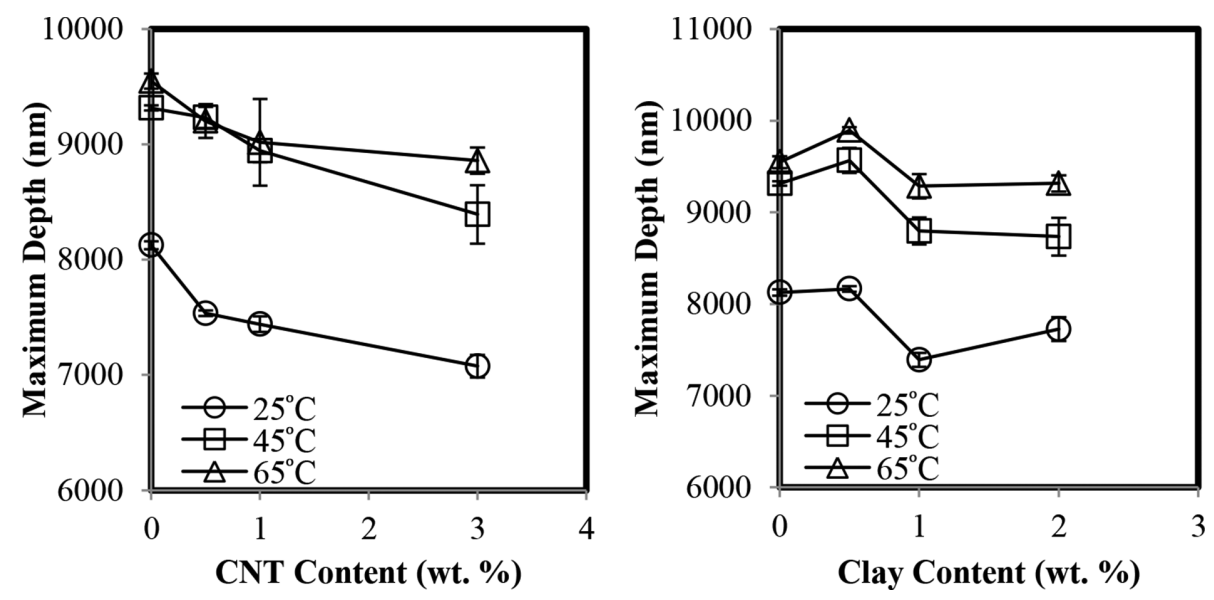

Figure 6: Dependency of maximum indentation depth on the nanoparticle loading and temperature. 


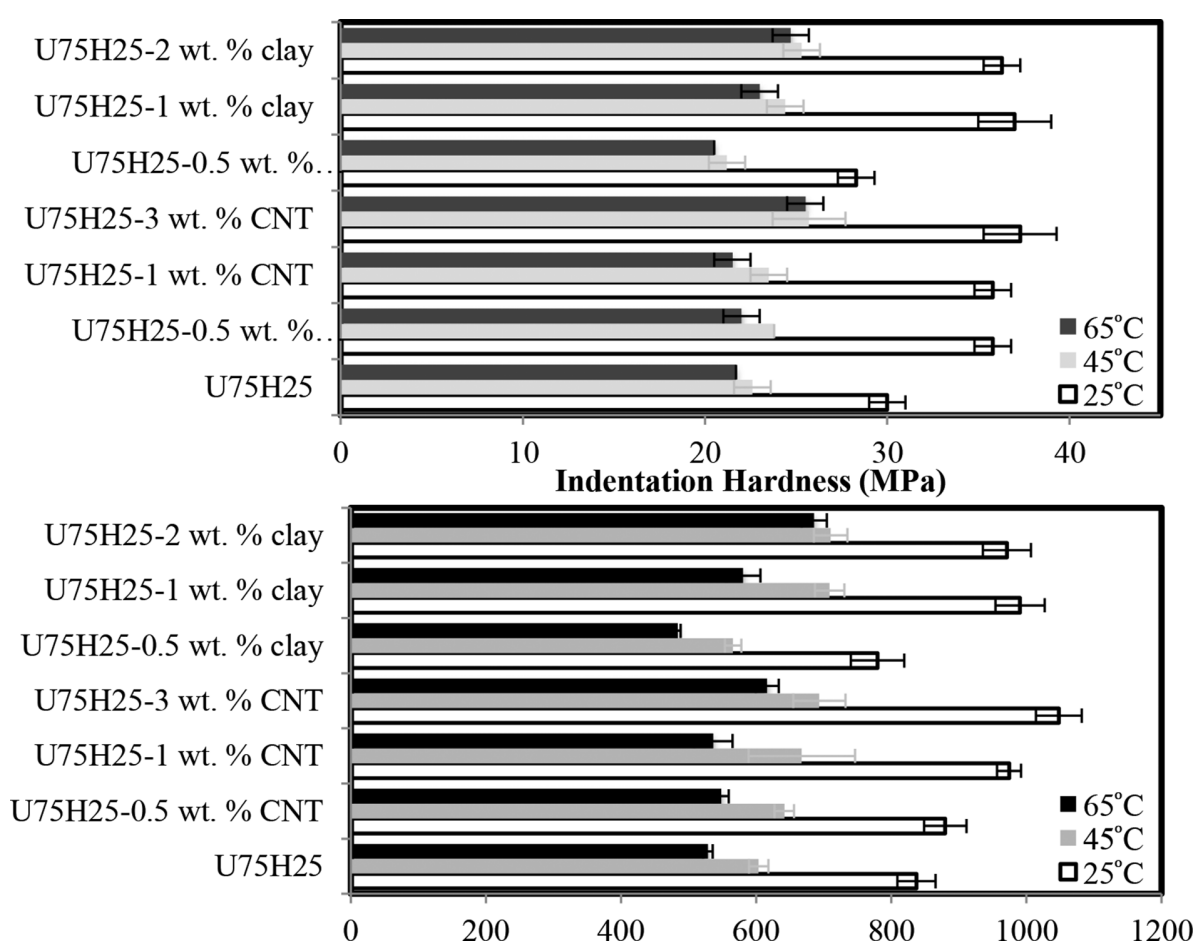

Figure 7: Effect of temperature on the indentation hardness and elastic modulus.

and $35 \%$. Further reduction in the elastic modulus values (in the range of 4-21\%) can be seen after an additional temperature increase of $20^{\circ} \mathrm{C}$.

\section{CONCLUSIONS}

It is important to investigate the near-surface properties of polyethylene-based nanocomposites at various temperatures to provide sufficient information about their properties at or near to their in-service temperatures. The incorporation of MWCNT and clay nanoparticles showed a significant increase in the indentation resistance, indentation hardness and elastic modulus of polyethylene materials at room temperature. However, these properties were significantly dependent on the ambient temperature. Increasing temperature resulted in a significant reduction in the indentation resistance, hardness and elastic modulus, which indicated a thermal softening of the materials. The addition of nanoparticle resulted in improvements in the near-surface properties at both room and high temperatures.

\section{ACKNOWLEDGEMENT}

Authors thank EPSRC and DSTL for funding support for the project.

\section{REFERENCES}

[1] Fischer-Cripps, A.C., Nanoindentation, Springer-Verlag, New York, 2002. doi: http:// dx.doi.org/10.1007/978-0-387-22462-6 
[2] Aldousiri, B., Dhakal, H.N., Onuh, S., Zhang, Z.Y. \& Bennett, N., Nanoindentation behaviour of layered silicate filled spent polyamide-12 nanocomposites. Polymer Testing, 30, pp. 688-692, 2011. doi: http://dx.doi.org/10.1016/j.polymertesting.2011.05.008

[3] Yusoh, K., Jin, J. \& Song, M, Subsurface mechanical properties of polyurethane/organoclay nanocomposite thin films studied by nanoindentation. Progress in Organic Coatings, 67, pp. 220-224, 2010. doi: http://dx.doi.org/10.1016/j.porgcoat.2009.10.003

[4] Wang, Z.Z., Gua, P. \& Zhang, Z., Indentation and scratch behavior of nano-SiO $2 /$ polycarbonate composite coating at the micro/nano-scale. Wear, 269, pp. 21-25, 2010. doi: http://dx.doi.org/10.1016/j.wear.2010.03.003

[5] Alghamdi, A.S., Ashcroft, I.A., Song, M. \& Cai, D., Morphology and strain rate effects on heat generation during the plastic deformation of polyethylene/carbon black nanocomposites. Polymer Testing, 32(6), pp. 1105-1113, 2013. doi: http://dx.doi. org/10.1016/j.polymertesting.2013.06.013

[6] Alghamdi, A.S., Ashcroft, I.A. \& Song, M., Mechanical characterisation of novel polyethylene nanocomposites by nanoindentation. Proc. of the 6th Int. Conf. on Computational Methods and Experiments in Materials Characterisation, WIT Transactions on Engineering Science, Vol. 77, Italy, 2013. doi: http://dx.doi.org/10.2495/mc130081

[7] Sreekanth, P.S.R. \& Kanagaraj, S., Assessment of bulk and surface properties of medical grade UHMWPE based nanocomposites using Nanoindentation and microtensile testing. Journal of the Mechanical Behavior of Biomedical Materials, 18, pp. 140-151, 2013. doi: http://dx.doi.org/10.1016/j.jmbbm.2012.11.011

[8] Gorwade, C.V, Alghamdi, A.S., Ashcroft, I.A., Silberschmidt, V.V. \& Song, M., Finite element analysis of the high strain rate testing of polymeric materials. Journal of Physics: Conference Series of Modern Practice in Stress and Vibration Analysis (MPSVA 2012), 382, 012043, Glasgow, UK, 2012. doi: http://dx.doi.org/10.1088/17426596/382/1/012043

[9] Seltzer, R., Kimb, J.K. \& Mai, Y.W., Elevated temperature nanoindentation behaviour of polyamide 6. Polymer International, 60, pp. 1753-1761, 2011. doi: http://dx.doi. org/10.1002/pi.3146

[10] Fulcher, J.T., Lu, Y., Tandon, G.P. \& Foster, D.C., Thermomechanical characterization of shape memory polymers using high temperature nanoindentation. Polymer Testing, 29, pp. 544-552, 2010. doi: http://dx.doi.org/10.1016/j.polymertesting.2010.02.001

[11] Lu, Y.C., Jones, D.C., Tandon, G.P., Putthanarat, S. \& Schoeppner, G.A., High temperature nanoindentation of PMR-15 polyimide. Experimental Mechanics, 50, pp. 491-499, 2010. doi: http://dx.doi.org/10.1007/s11340-009-9254-5

[12] Oliver, W.C. \& Pharr, G.M., An improved technique for determining hardness and elastic modulus using load and displacement sensing indentation experiments. J. Mater. Res., 7(6), pp. 1564-1583, 1992. doi: http://dx.doi.org/10.1557/jmr.1992.1564

[13] Humbert, S., Lame, O. \& Vigier, G., Polyethylene yielding behaviour: what is behind the correlation between yield stress and crystallinity? Polymer, 50(15), pp. 3755-3761, 2009. doi: http://dx.doi.org/10.1016/j.polymer.2009.05.017 